\title{
Stay or Go Back? An Exploratory Study on Educational Decision-Making of Chinese Visitant Parents
}

\author{
Haiping Hao, Patricia J. Larke \\ Texas A\&M University, College Station, USA
}

\author{
Song An \\ University of Texas at El Paso, El Paso, USA
}

\begin{abstract}
Visitant family is a growing trend of global migration that addresses a family's decision about the education of their school-age children. For example, with an increase in China's education and economy initiatives, there are many Chinese school-age children who come to the United States (U.S.) every year accompanying their parents. Many of visitant parents are mothers, who temporarily study or work in the U.S.. One major issue facing these families is the decision to "stay" here (the U.S.) or "go back" to their home country for the continued education of their children. School choice, as part of their educational decision-making, is one of the most important decisions made by visitant parents. Unfortunately, few studies address how visitant families make their "stay" or "go back" decision. Utilizing a qualitative research method, three participants were interviewed about their "stay" or "go back" decision that yielded three themes. The themes were: (a) performance and characteristics of children; (b) parental education perceptions, beliefs, and expectations; and (c) parental employment decisions. In addition, the study provides a concept map that may be used by parents in their decision-making process.
\end{abstract}

Keywords: comparative education, education and culture, family education

\section{Introduction}

There is a new trend of global migration that addresses a family's decision about the education of their school-age children. This trend is an indirect result of an increase in female immigrants, many of whom have school-age children. Female migrants have received more attention all over the world (Castles \& Miller, 1998). As Huang and Yeoh (2005) stated, "The education of the children has become a major 'project' requiring the relocation of one or more members of the family to a different country" during recent decades. For example, some researchers noticed the phenomena of Chinese "study mothers" and their transnational families in Singapore. For these mothers who accompany their studying children in Singapore, children' education and future are key factors in the transnational decision of families with sacrificing mothers' personal benefits and identities (Huang \& Yeoh, 2005; 2011). Families of "study mothers" can be regarded as a category of "astronaut households" (Waters, 2002). Similarly, "astronaut households" is another term used to represent those locationally split but transnationally linked families. This type of family also aims at pursuing "Western education”. In the beginning, these families are often confronted with difficulties (e.g., language and culture), but the situation improves as they become more familiar with their new environments (Waters, 2002; 2003). Their children are often called "parachute kids" or "satellite kids" who ranged from ages 8 to 17 (Tsong \& Liu,

Haiping Hao, Ph.D. candidate, research assistant, Department of Teaching, Learning and Culture, Texas A\&M University. Patricia J. Larke, Ed.D., professor, Department of Teaching, Learning and Culture, Texas A\&M University. Song An, Ph.D., assistant professor, Department of Teacher Education, University of Texas at El Paso. 
2009; Waters, 2003; Zhou, 1998). Although these kids normally adjust to the local school and life more quickly than their parents, researchers caution parents about the impact students encounter from having high expectations from their families.

With an increase in China's education and economy initiatives, there are many Chinese school-age children who come to the United States (U.S.) every year accompanying their parents. Many of them are mothers, who temporarily study or work in the U.S.. One major issue facing these families is their decision to "stay" here (the U.S.) or "go back" to their home country for the continued education of their children. School choice, as part of their educational decision-making, is one of the most important decisions made by visitant parents (Pang \& Appleton, 2004). Due to differences between Chinese and American educational systems, the decision of going back to intensive Chinese learning style is challenging, especially for their early adolescent children. Usually, the parents of these families are visiting scholars or international students with J-1 or F-1 visa. Many of them have high-level educational background and decent jobs in China; and they-if given opportunities — can seek employment in the U.S.. These families are identified as "visitant" (vs. resident) families. These families have certain freedoms to make decisions for their child's education transnationally.

Few research studies have focused on how visitant families make their decisions. School choice, as part of educational decision-making, is one of the most important decisions that parents need to make (Foskett \& Hemsley-Brown, 2001). The guiding research question in the study was: What do Chinese visitant parents share about their "stay" or "go back" decision-making process when making a decision about their child's education? As such, this article will share: (a) the results of a qualitative study involving three Chinese visitant parents; and (b) a concept map that visitant parents may use to make "stay" or "go back" decision.

\section{Method}

To respond to the research question, a qualitative research method was used to interview and analyze responses of three participants. The study was approved by the Institutional Review Board.

\section{Participants}

Purposive sampling was used to select the participants for the study. Qualitative researchers can choose the sample, which will provide the most valuable information (Merriam, 2009). Using convenience sampling, the principal investigator began with her teenager daughter's friends aged between 11 and 13 years old. This process yielded four participants, three females and one male. However, only the female voices are included in the study. The three participants' demographic information is presented in Table 1. The principal researcher was the instrument of this investigation and an insider who shared similar identities and experiences as the three participants.

Table 1

Demographic Information of the Three Participants

\begin{tabular}{|c|c|c|c|c|c|c|c|}
\hline Informants & Gender & Age & $\begin{array}{l}\text { Education } \\
\text { experience }\end{array}$ & $\begin{array}{l}\text { Professional } \\
\text { rank }\end{array}$ & Current status & $\begin{array}{l}\text { Child’s educational } \\
\text { experience }\end{array}$ & Husband's status \\
\hline Du & Female & 39 & $\begin{array}{l}\text { Doctoral } \\
\text { degree }\end{array}$ & $\begin{array}{l}\text { Associate } \\
\text { professor }\end{array}$ & $\begin{array}{l}\text { Visiting scholar } \\
\text { with J-1 visa }\end{array}$ & $\begin{array}{l}\text { Jerry came here in April } \\
2009, \text { now in grade } 6\end{array}$ & $\begin{array}{l}\text { Temporary worker in } \\
\text { the U.S. }\end{array}$ \\
\hline Sun & Female & 40 & $\begin{array}{l}\text { Doctoral } \\
\text { degree }\end{array}$ & $\begin{array}{l}\text { Associate } \\
\text { professor }\end{array}$ & $\begin{array}{l}\text { Visiting scholar } \\
\text { with J-1 visa }\end{array}$ & $\begin{array}{l}\text { Cindy came here in May } \\
2010 \text {, now in grade } 7\end{array}$ & $\begin{array}{l}\text { Faculty in an } \\
\text { American university }\end{array}$ \\
\hline Yao & Female & 42 & $\begin{array}{l}\text { Doctoral } \\
\text { degree }\end{array}$ & $\begin{array}{l}\text { Associate } \\
\text { professor }\end{array}$ & $\begin{array}{l}\text { Visiting scholar } \\
\text { with J-1 visa }\end{array}$ & $\begin{array}{l}\text { Jenny came here in } \\
\text { December 2010, now in } \\
\text { grade } 7\end{array}$ & $\begin{array}{l}\text { Professor in a Chinese } \\
\text { university }\end{array}$ \\
\hline
\end{tabular}




\section{Data Collection and Analysis}

A semi-structured, open-ended questionnaire consisting of 15 questions was used in each interview. The questions were similar for all three interviews, but varied in wording and orders, which were adjusted in terms of the effect of the last interview and the context of the current one (Merriam, 2009, p. 90). An example of a question was, "If it is possible, where do you want your child to study? Why?". All interviews were audio-recorded with prior permission, and field notes were taken during the interviews. The interview time was between one and two hours. All the interviews were conducted in Chinese, and transcripts were translated into English. For ensuring internal validity, member checks were employed to rule out misinterpreting (Merriam, 2009, p. 217). The participants were given an opportunity to view the printed copies of the transcripts and confirm several translations.

Thematic analysis was the major method for analyzing the data (Riessman, 2008). The analysis began from open coding. First, the data were broken into the minimum meaning units (Coffey \& Aakinson, 1996), and the transcripts were coded one line after the other. This process identified 20 categories in which three themes emerged (Cresswell, 2007).

\section{Findings}

The parental decisions to "go" or "stay back" were centered around three themes: (a) performance and characteristics of children; (b) parental education perceptions, beliefs, and expectations; and (c) parental employment decisions. Each of the three themes is discussed below.

\section{Three Themes}

Theme 1-Performance and characteristics of children. The learning experiences - that include a child's attitude, behavior, and school performance in China or America — can be good or bad according to these mothers' criteria. For example, Sun said, "She (Cindy) likes to go to school in both countries, although she welcomes weekends. Her scores are good in both places". The parents identified two characteristics of the children, "special" and "normal". In Du' eyes, her son Jerry was a special boy: clever (had good music hearing, liked to do manipulatives) and independent (with strong individuality). She repeated, "He has too many ideas", "He always lives in his mind", and "He performed differently in nearly every aspect under the two educational systems". In China, he was addicted to playing digital games, and his grades went down dramatically. On the contrary, in America, "He changed a lot, comparing with before. He is active; he likes his school now". Du thought Chinese education was not an ideal system for her son's special characteristics, while Sun thought Chinese education was better for her daughter because she was a normal girl. Sun said, "She has no exclusive upward motivation" and "American education is good for those talented children, but most children are normal. They need pushing".

Theme 2-Parental education perceptions, beliefs, and expectations. When parents discussed their perceptions of education, they discussed it from a China vs. America's strengths vs. weaknesses perspective. In the interviews, the importance of strengths of education in certain countries reflected their parental preferences. Each mentioned strengths and weaknesses in both countries and described how Chinese education could meet their needs for more practices and content. They had personal beliefs about education in relation to the quality of teachers and schools and beliefs about their child's development. They felt that parents should try to give their children the best education that they could give. For example, Du thought that music and sports were very important for children and Sun talked about children learning the ability to have self-control. All parents had 
high expectations of their children's academic performance. In fact, this study and many other studies have supported this view (Chao, 1996; Lin \& Fu, 1990). According to Sun, "She will finish the requirements, but only this. I hope she can read more, yet, she cannot do".

Theme 3-Parental employment opportunity. For many Chinese, obtaining an American visa is difficult. This is a barrier in the "stay" or "go back" decision. While many visitant mothers want their children to accept Western education, quite often they have to abandon their comfortable lives, positions, friends, and even dignity, because they are unable to obtain similar employment positions in America that they already had in China. Both Sun and Yao spoke about this dilemma. Sun said that she would not abandon her "good" position in China. Yao has the similar situation, but she wanted to make a sacrifice for her daughter, so she said, "Maybe I can come again as a post doctor".

\section{Individual Context Influencing Parents to Make a Decision}

Every visitant family had their own story about their child's educational choice. Making "stay" or "go back" decision is complicated as demonstrated in excerpts from Sun's story. Sun thought her daughter Cindy did well in both countries. She said, "She likes to go to school in both countries, although she enjoys the weekends. Her grades were good in both places”. When comparing the two educational systems, she said:

It is better than having middle school education in China. The bases of math are grounded. There are history and geography lessons in Chinese middle school. Here, there is no exclusive geography. But the design here is good: Texas history is learned first. It is said that there are American history and world history in high school. In China, there are no regional histories like Shandong history, just Chinese history, but that is fine. Chinese education values practice. It is right for students' academic background is strong. Children in America need to take standard exams to enter the university, too. In this aspect, Chinese educational system is good. (Children can) learn more than students here.

Sun also talked about the strengths of American education, but added some concerns. For example, as she stated here, "Students can choose classes freely according to their interests but students have no long-term classmates... Homework is interesting, but she is too comfortable here". She continued, "The time she spends at home is too long. After 3:40 p.m. until night? Precious time idles away”. Although her husband has already worked here, she cannot give up the good position in a university in China. Clearly, her story shares how she made decisions that were evident in the three themes. She based her decision "to stay" or "go back" on: (a) the performance and characteristics of her child; (b) perceptions, beliefs, and expectations of the school system; and (c) her employment decisions.

\section{Concept Map of Parents' “Stay” or “Go Back” Decision}

Further, findings from the transcript analysis were organized into the conceptual map (see Figure 1). The overall organization of the concept map mirrors the general complexity of understanding the process of a parent's decision-making regarding her child's education. It should be noted here that although this concept map can show the interaction among several key factors, it is not a universal one.

In Figure 1, the three key factors include child performance (good in America or good in China), characteristics (special or normal), and parental perception of education (strengths of American education or Chinese education). Each of them has two possible directions: good or bad. For example, the child, Jerry, was independent and performed well in America, so his mom Du thought that the American education would be the best fit for him. In contrast, Sun thought that Cindy would have a better fit in Chinese education environment because it would give her the extra push. 


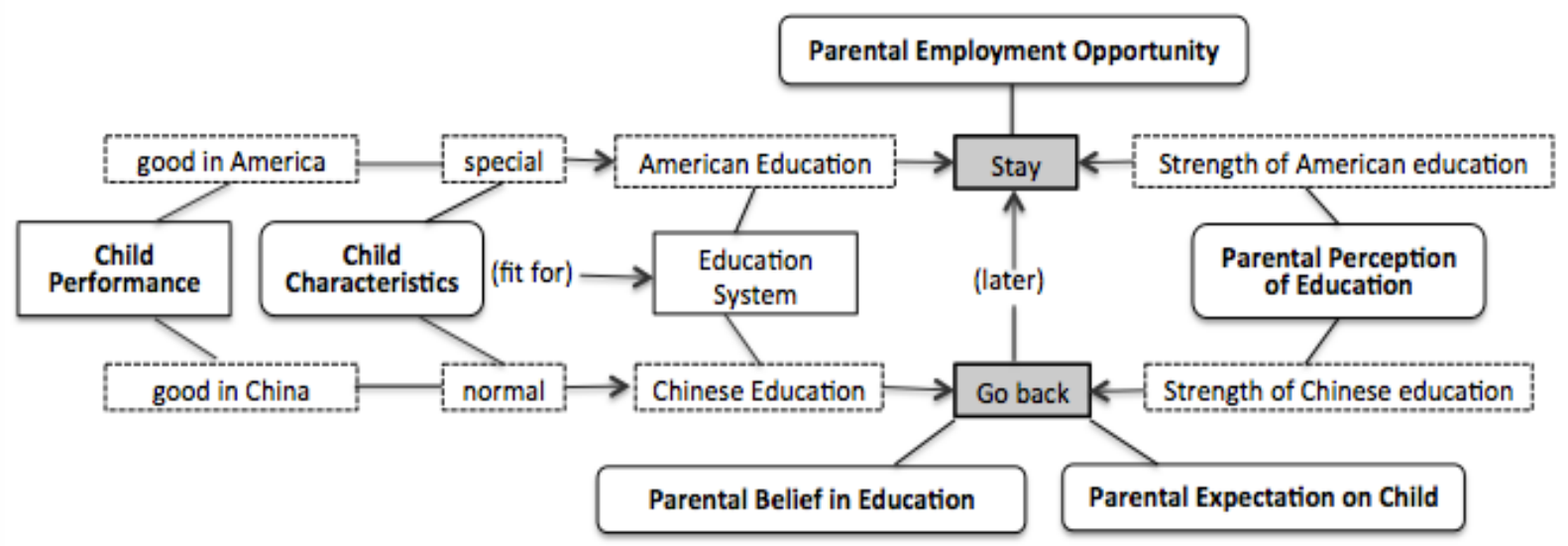

Figure 1. Concept map of parental decision-making process for child education.

Among these factors, child performance is a significant factor for parents to make decisions. At the same time, nearly all parents contributed child characteristics to the child's academic performance. For example, Du thought her son failed in China, because his characteristics were special, meaning he was too independent, and China could not meet his needs. Sun thought that her daughter was just among normal children, who needed to be pushed by others to make progress. However, the child performance factor can affect parental perceptions of education. For example, Jenny's achievement was not good in China, and it had improved since Jenny came to the U.S.. Her mom, Yao, still preferred Chinese education because she thought that students could learn more in school.

\section{Discussion and Conclusion}

Even though every visitant family has their own story about their child's educational choice, there were three areas noted in this study that parents used to make their "stay" or "go back" decision. They made decisions based on: (a) performance and characteristics of children; (b) parental education perceptions, beliefs, and expectations; and (c) parental employment decisions. Among them, child performance and characteristics and parental perception, beliefs, and expectations are crucial. If a child's "good" performance in the U.S. is consistent with the parent's positive perception of American education, the final decision is most likely to go on studying here. On the other hand, if a child's "good" performance in China is consistent with the parent's positive perception of Chinese education, the final decision is most likely to go back to China. However, if child performance is not so obvious to be differentiated from each other in two countries, then parental perceptions of education will be more prominent in their decision regarding further education.

It is interesting to note the similarities among the three informants. All of them emphasized that practices were necessary, especially for mathematics. Du is a firm advocate of American education, but she said at the end of the interview, "Hopefully math can be strengthened a little more in America. Practice makes perfect. You have to practice a lot if you expect solid basic skills". And similar to other studies, Chinese mothers are dedicated to their children’s education (Huang \& Yeoh, 2005; Chao, 1996; Lin \& Fu, 1990). "Either way, either of us will sacrifice our personal interest”, Yao replied when asked to decide which side she and her husband would take for their child's education. Also, the principal investigator also heard from others that Du's family would immigrate to Canada for Jerry's education, sacrificing all she had in China. These choices are related to 
traditional Chinese culture, which holds that education of the next generation has priority over all other needs of the family.

We have to consider the social and cultural contexts of these Chinese parents behind the phenomenon of educational decision-making. First, in China, the "only child" policy and economic development in recent decades make people more willingly to possibly invest into education with high expectations on their children (Lee, 2012; Zhu \& Zhang, 2008). All these three participants had an only child.

In addition, we cannot ignore the influence of Confucianism. Family is valued as the center of people's daily life, which also can be applied in education ("family business"). Chinese parents hold the belief that they are responsible for children's academic achievement. Both parents and children have high pressures and a stake in each other's success (Huang \& Gove, 2012). That is why many parents, especially mothers, are endowed with the spirit of self-sacrifice. Further, in Confucianism family, hierarchy is a core spirit, which affects education decision-making. Children should respect and obey parental authority (Huang \& Gove, 2012; Wang \& Faldowski, 2014). Comparatively, even immigrant Chinese mothers have higher parental control and emphasis on their children's achievements than their American counterparts ( $\mathrm{Lin} \& \mathrm{Fu}, 1990$ ). Thus, no wonder the informants almost mentioned nothing about their children's intention in interviews, while child performance and parental perception of education are the core factors for parents to make decisions.

\section{References}

Castles, S., \& Miller, M. J. (1998). The age of migration: International population movements in the modern world (2nd ed.). London, U.K.: Macmillan Press.

Chao, R. K. (1996). Chinese and European American mothers' beliefs about the role of parenting in children's school success. Journal of Cross-Cultural Psychology, 27(4), 403-423.

Coffey, A., \& Aakinson, P. (1996). Concepts and coding. In Making sense of qualitative data: Complementary research strategies. Thousand Oaks, C.A.: Sage.

Cooksey, R. W. (1996). Judgment analysis: Theory, methods and applications. London, U.K.: Academic Press.

Cresswell, J. L. (2007). Qualitative inquiry \& research design (2nd ed.). Thousand Oaks, C.A.: Sage.

Fong, V. (2004, November). Filial nationalism among Chinese teenagers with global identities. American Ethnologiste, 31(4), 631-648.

Foskett, N., \& Hemsley-Brown, J. (2001). Choosing futures: Young people's decision-making in education, training, and careers markets. New York, N.Y.: Routledge.

Gorard, S. (1997). School choice in an established market. Aldershot: Ashgate.

Gorard, S. (1999). Well, that about wraps it up for school research: A state of the art review. School Leadership and Management, 19(1), 25-47.

Hammond, K. R. (1996). Human judgment and social policy: Irreducible uncertainty, inevitable error, unavoidable injustice. New York, N.Y.: Oxford University Press.

Huang, G. H. C., \& Gove, M. (2012). Confucianism and Chinese families: Values and practices in education. International Journal of Humanities and Social Science, 2(3), 10-14.

Huang, S., \& Yeoh, B. A. (2005). Transnational families and their children's education: China's "study mothers” in Singapore. Global Networks, 5(4), 379-400.

Huang, S., \& Yeoh, B. S. (2011). Navigating the terrains of transnational education: Children of Chinese "study mothers" in Singapore. Geoforum, 42(3), 394-403.

Janis, I. L., \& Mann, L. (1977). Decision making: A psychological analysis of conflict, choice and commitment. New York, N.Y.: Macmillan Publishing/The Free Press.

Klein, G. (1998). Sources of power: How people make decisions. Cambridge, M.A.: MIT Press.

Lee, M. (2012). The one-child policy and gender equality in education in China: Evidence from household data. Journal of Family and Economic Issues, 33(1), 41-52. 
Li, Y., Chen, X., \& An, S. (2009). Conceptualizing and organizing content for teaching and learning in selected Chinese, Japanese and U.S. mathematics textbooks: The case of fraction division. International Journal on Mathematics Education, 41, 809-826.

Lin, C. C., \& Fu, V. R. (1990, April). A comparison of child-rearing practices among Chinese, immigrant Chinese, and Caucasian-American parents. Child Development, 61(2), 429-433.

Merriam, S. B. (2009). Qualitative research: A guide to design and implementation (3rd ed.). San Francisco, C.A.: Jossey-Bass.

Pang, B., \& Appleton, N. (2004). Higher education as an immigration path for Chinese students and scholars. The Qualitative Report, 9(3), 500-527.

Riessman, C. K. (2008). Narrative methods for the human sciences. Thousand Oaks, C.A.: Sage.

Tsong, Y., \& Liu, Y. (2009). Parachute kids and astronaut families. In N. Tewari, \& A. N. Alvarez (Eds.), Asian American psychology: Current perspectives (pp. 365-380). New York, N.Y.: Taylor \& Francis.

Wang, Y. C., \& Faldowski, R. A. (2014). Beliefs in the legitimacy of decision authority among Chinese adolescents and parents: A person-centered approach. Journal of Adolescence, 37(7), 1121-1132.

Waters, J. L. (2002). Flexible families? “Astronaut” households and the experience of lone mothers in Vancouver, British Columbia. Social and Cultural Geography, 3, 117-134.

Waters, J. L. (2003). "Satellite kids” in Vancouver: Transnational migration, education and the experiences of lone children. In M. Charney, B. S. A. Yeoh, \& C. K. Tong (Eds.), Asian migrants and education: The tension of education in immigrant societies and among migrant groups (pp. 165-184). London, U.K.: Kluwer Academic Publishers.

Zhou, M. (1998). "Parachute kids” in southern California: The educational experience of Chinese children in transnational families. Educational Policy, 12(6), 682-704.

Zhu, J., \& Zhang, J. (2008). Contemporary trends and developments in early childhood education in China. Early Years, 28(2), 173-182. 